\title{
Designing for Driver's Emotional Transitions and Rituals
}

\author{
Jiayu $\mathrm{Wu}$ \\ Intelligent Mobility Design Centre, \\ Royal College of Art \\ jiayu.wu@rca.ac.uk \\ Sheila Clark \\ Intelligent Mobility Design Centre, \\ Royal College of Art \\ sheila.clark@rca.ac.uk
}

\author{
Katrine Dalum Hesseldahl \\ Intelligent Mobility Design Centre, \\ Royal College of Art \\ katrine.hesseldahl@network.rca.ac.uk \\ Dan Quinlan \\ Intelligent Mobility Design Centre, \\ Royal College of Art \\ daniel.quinlan@rca.ac.uk
}

\author{
Samuel Johnson \\ Intelligent Mobility Design Centre, \\ Royal College of Art \\ samuel.johnson@network.rca.ac.uk \\ Dale Harrow \\ Intelligent Mobility Design Centre, \\ Royal College of Art \\ dale.harrow@rca.ac.uk
}

\begin{abstract}
Emotions are a topic of increasing interest in vehicle design and research as they have a substantive impact on people's behaviour, affecting driving performance and being a source of safety issues particularly on long journeys. However, emotions do not usually occur distinctly and individually and frequently transition and transform between states. It can be challenging to obtain information about the exact emotions drivers experience, especially when subtle. We present design-led research focusing on identifying scenarios that contain normally unarticulated emotions and mental reminders that drivers use to make a journey safer and develop concepts for in-vehicle interactions that assist with these rituals. As results of the research, we designed and user tested in-vehicle interactions for two emotional transition scenarios - pre-journey preparation ('Ready... Steady ... Relax') and checking the progress of a journey ('Driving Whisper').
\end{abstract}

\section{CCS CONCEPTS}

- Human-centered computing; • Interaction design; • Interaction design process and methods; • User centered design;

\section{KEYWORDS}

User-vehicle experience, Emotional transitions, Vehicle rituals, Research through design

\section{ACM Reference Format:}

Jiayu Wu, Katrine Dalum Hesseldahl, Samuel Johnson, Sheila Clark, Dan Quinlan, and Dale Harrow. 2021. Designing for Driver's Emotional Transitions and Rituals. In 13th International Conference on Automotive User Interfaces and Interactive Vehicular Applications (AutomotiveUI '21), September 09-14, 2021, Leeds, United Kingdom. ACM, New York, NY, USA, 11 pages. https://doi.org/10.1145/3409118.3475143

Permission to make digital or hard copies of all or part of this work for personal or classroom use is granted without fee provided that copies are not made or distributed for profit or commercial advantage and that copies bear this notice and the full citation on the first page. Copyrights for components of this work owned by others than the author(s) must be honored. Abstracting with credit is permitted. To copy otherwise, or republish, to post on servers or to redistribute to lists, requires prior specific permission and/or a fee. Request permissions from permissions@acm.org.

AutomotiveUI '21, September 09-14, 2021, Leeds, United Kingdom

(c) 2021 Copyright held by the owner/author(s). Publication rights licensed to ACM. ACM ISBN 978-1-4503-8063-8/21/09..\$15.00

https://doi.org/10.1145/3409118.3475143

\section{INTRODUCTION}

Research into driving related emotions has been conducted in areas including what emotions are detectable and identifying research outputs that can be applied to improve vehicle functionality $[13,4$.$] .$ It was reported that there are two main strategies for enhancing vehicle safety for drivers - countersteering negative emotions and adapting car functionality to the driver's emotions [6]. Music [21], affective voices [16] and aesthetically pleasing environments [20] have been studied to investigate driver interventions that can steer negative emotions into their positive counterparts. Concepts have also been explored to adapt vehicle functions to driver's emotions. The Toyota FV2 concept recognises and responds to the user's emotions through the vehicle's appearance and by switching between driving modes. The Honda NeuV concept collects user's physiological data and responds by adjusting vehicle systems which are reflected in the user interfaces. However, studies also show that positive emotions are usually related to drivers enjoying their independence, wanting genuine experience and 'back-to-basic' modes [3], and negative emotions may be generated by patronising assistant systems [4.]. Vehicle functions such as alerts to prevent fatigued driving leading to unsafe situations have been applied to working vehicles such as lorries and vans. These research and design concepts mainly focus on detecting emotions that have already happened in order to apply interventions to cope with the situation. To the authors' knowledge, research has seldom studied the fragmented actions that drivers usually perform to help them counteract negative emotions when setting off, driving and on arrival.

An important area of research supporting driver's emotional experiences is how one defines emotions, as they usually do not occur distinctly and individually, and further emotions can be triggered as they transition and transform from one to another $[1,5,8]$. There are moments that drivers' emotional states switch between two or more modes as they are constantly traveling through different locations and changing situations. In order to master their emotions drivers often have habits or a sequence of actions they take to help release negative emotions throughout a journey. We call the moments with actions which help to master emotions 'emotional transition scenarios', an overlooked area in driving related emotions research. We believe that understanding drivers' natural actions that allow them to place their minds in clear, calm and perfect emotional states (to complete an emotional transition) will lead us to opportunities for designing adaptive vehicle functions. 
The research is divided into defining key emotional transitions and detailed actions with car users, creating visualised scenarios to demonstrate design challenges, and developing interface and interaction designs to respond to the design challenges. Detailed suggestions for how future vehicle designs could consider users' subtle emotional transitions and avoid unsafe situations are discussed.

\section{RELATED WORK AND AIMS OF OUR WORK}

Previously, research around drivers' emotions generally falls into four areas:

- summarising driving related emotion keywords/emotional situations to measure or detect emotions $[3,13]$

- leverage media to transform emotions for safe driving [20, 21]

- study vehicle-user interactions using different sources of sensory input $[16,19]$

- explore affective strategies to improve drivers' emotions $[6,4$.

Research discussing car related emotional scenarios includes Jeon \& Waler [13] reporting how emotion-inducing scenarios are driving irrelevant in-vehicle contexts, driving relevant in-vehicle contexts and driving irrelevant out-of-vehicle contexts. They briefly mention other situations that might happen just before driving and that could affect driving performance; and Braun et al. [3] who summarised typical emotional situations encountered while driving (e.g. driving quality self, driving quality others), investigated the triggers and provided general design recommendations focusing on driving interfaces.

Most vehicle related emotions are involved in "learning novel features" and "encounter learnability flaws" [14] which are reflective and dependent on vehicle settings and designs. Eyben et al. stated that driver's emotion should support attention, judgement of traffic situations, driving performance, compliance, decision making, strategic planning and communication with other road users [6]. Our research focused on identifying key emotional transitions before, during and after journeys, generating design strategies and concepts to improve car functions avoiding negative operation related emotions before they happen. The aim is to design and test strategies to support driving tasks by a series of physical preparation which translates to mental readiness.

Users generate emotion to minimise errors, interpret functionality, or obtain relief from the complexity of a task such as driving. Focus on emotional transitions rather than 'short and reflexive emotional responses such as sadness, frustration and joyfulness' [8], especially subtle emotional transitions during the whole journey, sometimes including periods before and after, leads to a holistic view of interior design leading to a more natural experience when compared to studies focused on dashboard design, ambient light or voice assistance. Design-led research is especially valuable when addressing research questions as it provides approaches for defining experience from users' own perceptions [7, 9], framing emotional transition processes in the whole journey experience or life cycle of a product [14], and provides unique methods to collect lived experiences representing emotional transitions [10, 22, 23]. Applying design research, we found unarticulated and overlooked facts for users to manage their emotions when driving and define innovation spaces for automotive manufacturers.

\section{METHODOLOGY}

The research consists of two phases - user studies and concept design. In the User Studies phase, we conducted telephone interviews $(\mathrm{N}=21$, details in 3.3), three enactment workshops $(\mathrm{N}=7$ in total, details in 3.4) and journey shadowing $(\mathrm{N}=4$, details in 3.4) to identify key scenarios for emotional transitions in the context of vehicle use. By reviewing user data from key scenarios, we defined two focused design spaces and generated contextual videos for pre-journey preparation and checking the progress of a journey. We hosted a further two enactment workshops ( $\mathrm{N}=9$, details in 3.5) to explore potential in-vehicle interactions based on the contextual videos. With detailed suggested interactions for the two design spaces, we moved on to the concept design phase which included an ideation workshop with four designers and three user researchers to generate design briefs which were then further developed into vehicle objects/extended functions described in two video demos, Ready. . .Steady. . .Relax and Driving Whisper. We were looking for a research approach to assist us define emotional transition scenarios and investigate fragmented actions during transition periods with car users. An approach that we found particularly effective was the concept of ritual [17].

\subsection{Ritual: a key to researching emotional transitions}

A key goal of the research was to explore the turning points when a driver is transitioning from one state of emotion to another, and all the events that help this process happen smoothly, so that natural in-vehicle interaction concepts supported by advanced technologies can emerge. We found that there are actions that drivers perform repeatedly during vehicle use which impart a significant meaning to their experiences related to emotional release. This includes playing certain types of music when stressed, double checking mirrors and the dashboard before moving and allowing for 'me time' driving at the end of a day. Ritual has been the word that we find best summarises these actions because it is normally related to emotion management. We employed 'ritual' as a research approach for defining emotional transitions for two reasons: 1) ritual is able to trigger in-depth conversations about emotional experience as it pushes answers that are reflective to one's habits and routines; 2) rituals are usually described step by step with rich details of actions, thinking and feelings which makes it a perfect tool to lead us to users' mental space.

\subsection{Ritual and driver experiences}

Rituals are often performed without deliberate thought as to the rationale that guides them. Ritual is about moment, narrative, meaning, gestures and sequence. Order is the key characteristic of the vehicle emotional experience because in the narrow in-vehicle space people's actions need to be ordered. Elapsed time is important to drivers, and most people feel relaxed if things are ordered. This leads us to look at the concept of ritual as sequence is the key to performing rituals. Our research has found ritualist driver experiences are mostly focusing on settling into the car including turning on 
Table 1: Rituals identified by interviewees related to transitioning from one emotion to another

\begin{tabular}{|c|c|c|}
\hline Name & Ritual action examples & Emotional transition \\
\hline Check and check again & $\begin{array}{l}\text { Repetitive actions to reduce anxiety such as double checking } \\
\text { if one has taken all one's possessions before starting journey }\end{array}$ & Calming \\
\hline Me time & $\begin{array}{l}\text { When travelling alone, typically at the end of the day, sitting } \\
\text { in the car, ensuring the windows are closed, selecting and } \\
\text { playing one's favourite music, enjoying the music alone }\end{array}$ & $\begin{array}{l}\text { Pausing allows a mood switch from } \\
\text { 'work mode' to 'home mode' }\end{array}$ \\
\hline Sense of achievement & $\begin{array}{l}\text { Checking the overall progress of the journey, more frequently } \\
\text { once past halfway }\end{array}$ & Uncertainty to satisfaction \\
\hline Setting the mood & $\begin{array}{l}\text { A set of actions always performed before starting a morning } \\
\text { commute such as checking and cleaning the windscreen and } \\
\text { windows and organising one's belongings }\end{array}$ & $\begin{array}{l}\text { Creating and maintaining a good mood } \\
\text { for the journey and the rest of the day }\end{array}$ \\
\hline Family time & $\begin{array}{l}\text { Getting children out of the door, putting them in the car, } \\
\text { setting off, having conversations, always playing the same } \\
\text { music/podcast, dropping them off for a class, waiting, picking } \\
\text { them up }\end{array}$ & $\begin{array}{l}\text { Remove the stress of a journey by } \\
\text { creating a happy atmosphere }\end{array}$ \\
\hline Clearing the mind & $\begin{array}{l}\text { Getting into a car after a busy day or to escape family chores, } \\
\text { driving to a favourite local destination or route }\end{array}$ & $\begin{array}{l}\text { A change of environment to process } \\
\text { and get rid of negative emotions }\end{array}$ \\
\hline Building confidence & $\begin{array}{l}\text { Ensuring everything perceived as needed to drive (e.g. keys, } \\
\text { sunglasses, rain clothing) is present, organising the car's } \\
\text { environment around themselves, putting every belonging into } \\
\text { its rightful place before driving }\end{array}$ & $\begin{array}{l}\text { From unprepared and anxious to } \\
\text { prepared and confident }\end{array}$ \\
\hline
\end{tabular}

music, tidying up and cleaning the car. Vehicle rituals are defined as a set of fixed, meaningful actions that people use to create a sense of control and feelings of safety and comfort [23].

Rituals are "functional through their performance, apart from their content" [2]. A driver goes through one state of mind to the other when performing driving tasks, for example, if it is a familiar route they know where to go and what to do without thinking. Rituals are also repeated actions and aims to "get those actions right" [15]. For example, a typical driving related emotional transition happens when drivers prepare their car for a trip and they go through the same process every time to make sure they are mentally prepared. "We need ritual to enable us to connect with our deepest thoughts and feelings, our nascent hopes and our debilitating fears... In an increasingly frantic world, it gives us an essential pause" [11]. Pause from the chaotic surroundings makes ritual essential for everyday life and similarly for drivers before going on an unfamiliar trip or seeking a mental pause in their own driving bubble. All these rituals are critical for drivers to manage their emotions and keep them safe on the road.

\subsection{Identifying typical emotional transitions in the context of vehicle use}

Twenty-one short telephone interviews were conducted with new and experienced drivers covering long distance travel and the daily commute (eleven male and ten female, ranging from twenty to eighty years old). This activity was used to collect insights about how people manage their emotions in car journeys. The interviewees were asked questions selected from a pool of fifteen questions categorised in three groups - routines of everyday travel, ritualistic moments of car trips and rituals around frequent journeys. We explained how we define rituals in driver experiences to the interviewees and asked them to identify rituals in relation to their driving experiences which when performed help them transform negative emotions into positive ones.

We found that emotional transitions are often triggered by the time of the day, the mood before and during driving, traffic situations and who the drivers are traveling with. Our findings show rituals, in relation to emotional transitions, are key to helping to manage emotions and often happen before and during journeys. Everyday commutes host the majority of journey rituals with long distance travel the second most common source. Major reasons for practicing driving related rituals include preparation and achieving a sense of accomplishment, having time to oneself including moments for emotional transitions, and having the feeling of having power to control the car.

\subsection{Investigating detailed scenarios around driver's emotional transitions}

Three enactment workshops with seven participants were conducted to explore details of emotional transition scenarios including when and where they happen, what objects were involved, how emotions change and the meaning of ritualistic actions to the drivers and why they perform them. The workshop attendees (ranging in age from twenty to forty years old) all had valid driving licenses and needed to have commuted or had experience of long-distance car journeys within the previous year. The workshops focused on everyday commutes and long journeys to unfamiliar destinations given these two areas were revealed to have the most driving rituals in the telephone interview sessions.

Before attending workshops, the participants were asked to bring one or more objects (or representations of objects) that they associated with "a meaningful action" that they often repeat when 


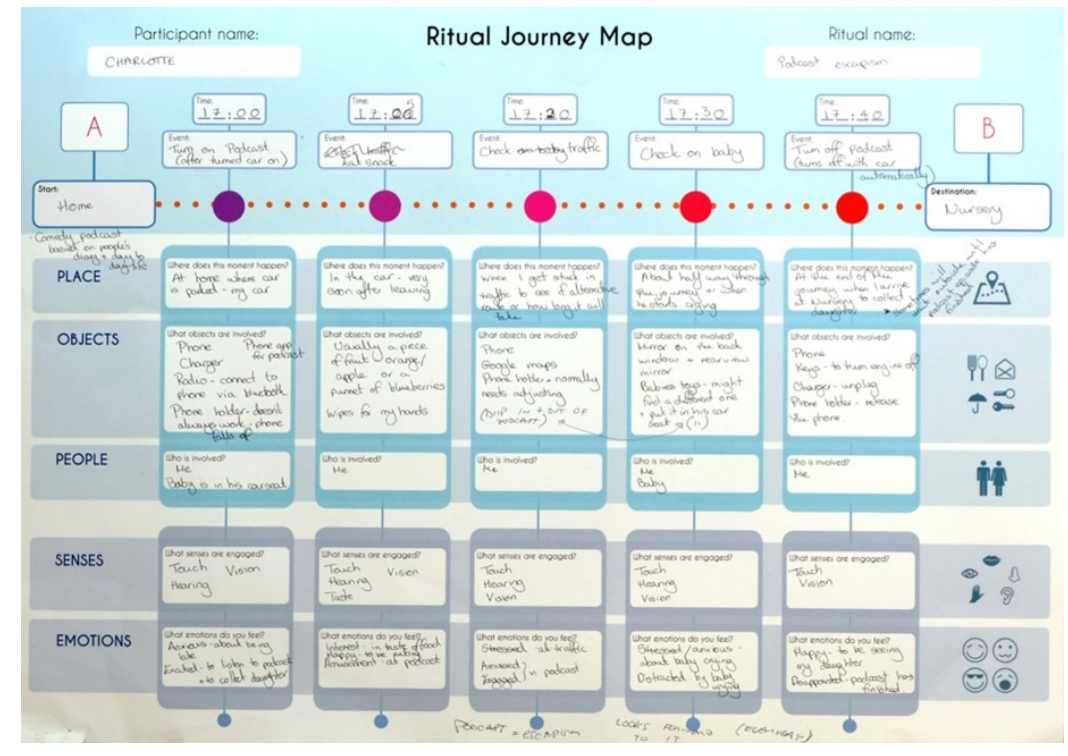

Figure 1: Ritual Journey Map

travelling. During the workshops we dissected each participant's journey step-by-step into stages to analyse their experiences which were recorded on a Ritual Journey Map (Figure 1). Cardboard props (Figure 2) were provided while workshop participants described their example journeys. The props represented items people take with them in their hands or pockets such as mobile telephones, dash cams and other everyday or travel related objects.

Two common emotional transition scenarios emerged from the workshops which form more focused design spaces for helping to sustain positive emotions and reduce negative emotions: 1) feeling ready: preparations before a journey and 2) Feeling in control: journey progress. We conducted four journey shadowing to gather in-depth interaction details of drivers and their cars to help us to identify interior design opportunities. Four experienced drivers were selected from previous workshop and interview participants. To investigate both scenarios we needed regular drivers in different stages of relationships with their cars, for example, a driver who has used the same car for years, users of a family car, and a driver using a new car. We followed the drivers in their cars as they undertook their daily journeys. Before participants got into their cars, and after they arrived at their destination, we assessed their emotional state using the Wheel of Emotions tool [18] (Figure 3) and our "HOW READY indication tool" (Figure 4). During the journey we observed and asked relevant questions about the relationship between car operation and emotional transitions (Figure 5). We asked different questions for each stage of the journey. For example, before the journey started, we asked about feelings regarding vehicle-user communication and in-car journey preparation. During the journey, questions were asked about mindset-shift and the feeling of going to a new place. At the end of the journey, questions were asked about car services and the driver's relationship with the car in general.

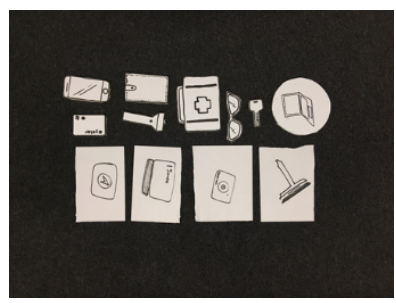

Figure 2: A driver illustrating their pre-driving ritual with a selection of devices and objects

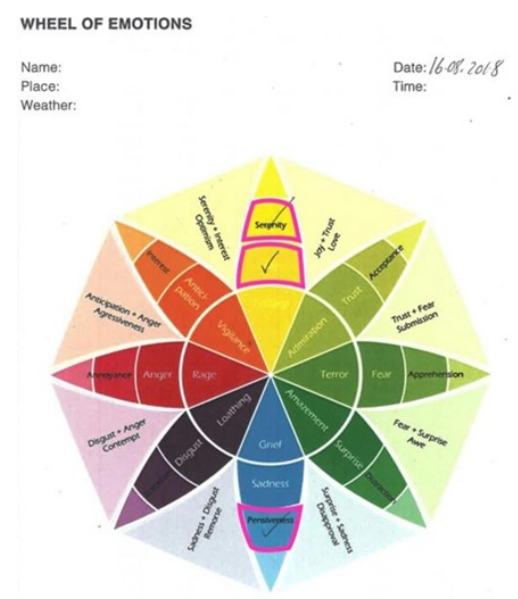

Figure 3: Wheel of Emotions tool [18]

\subsection{Designing in-vehicle interaction concepts}

Having defined two focused design spaces for ritualistic emotional transitions, we started forming design briefs to reflect demands 


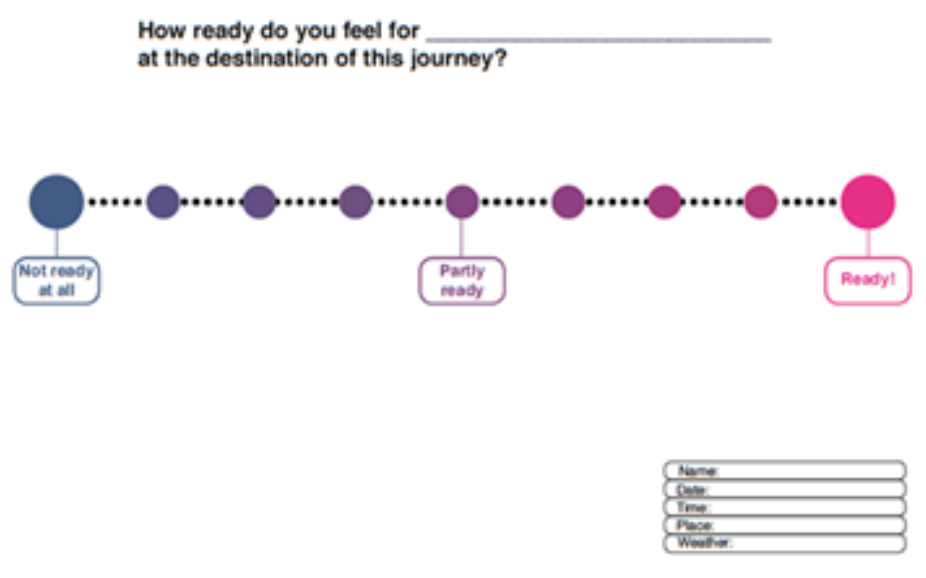

Figure 4: How Ready indication tool used before and after the journey
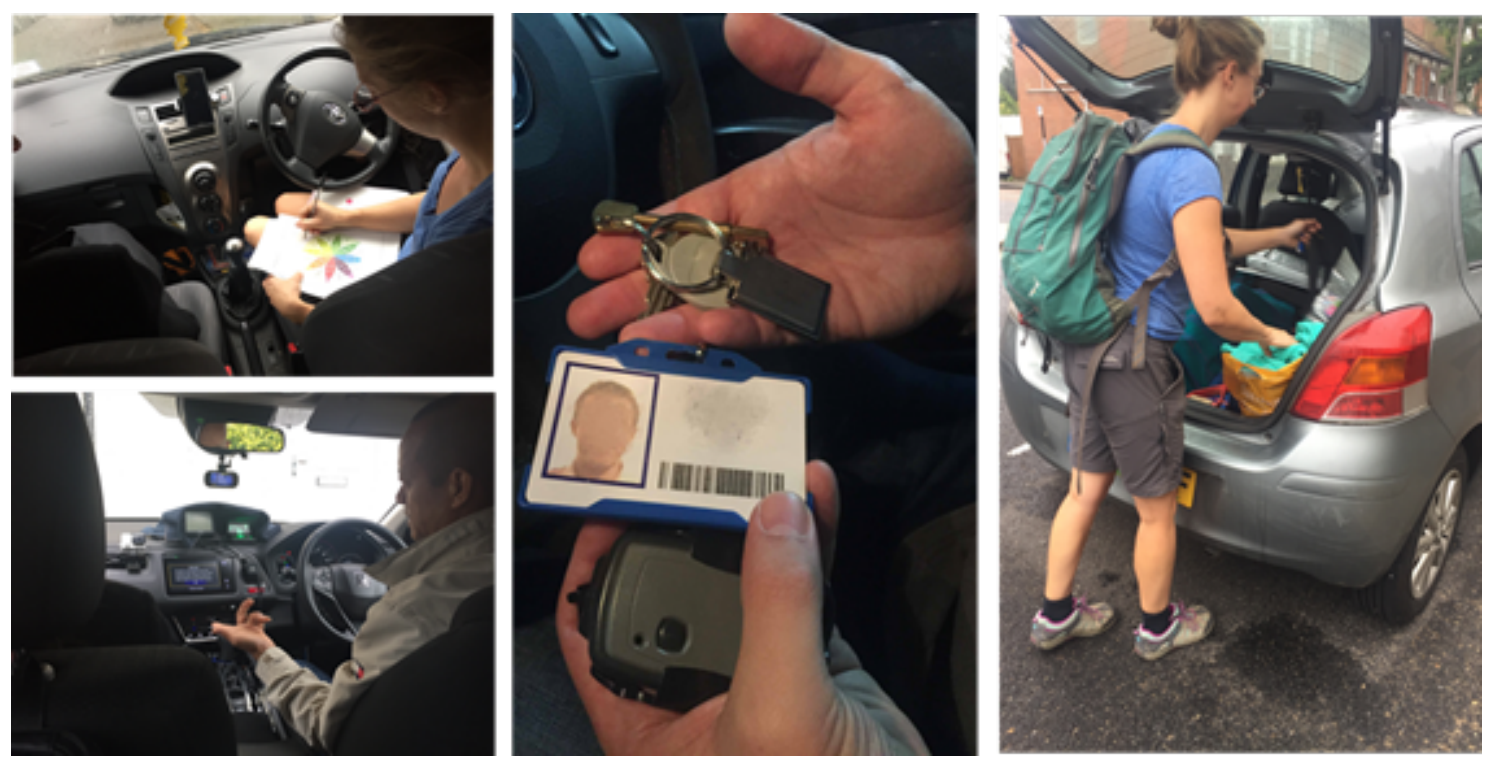

Figure 5: Behavioural details from journey shadowing. Left to right: Driver completing an emotional state of mind tool. Driver talking about vehicle gadgets. Belongings placed in the car by a driver on entry. A gardener packing their tools for work.

that drivers have to release or sooth their anxiety. When creating concepts we took into account current technology such as selfdriving and connectivity, and social/behavioural trends such as shifts from private cars to shared services. Design briefs lead to contextual videos to highlight where vehicle objects or extended functions could host and support emotional transitions, serving as researcher/driver communication tools in later user evaluations. Two further enactment workshops with nine participants were conducted to evaluate the design briefs and investigate vehicleuser interactions in order to turn concepts into tangible design features. Adjustments were made and video demos were developed to demonstrate specific vehicle function and interface designs. Ritualistic actions usually consist of steps to achieve a transition from one state of emotion to the other. We therefore designed our workshops to identify and document generic sequences of actions drivers undertake before setting off in their car and to monitor the route during a long distance journey.

For the Feeling Ready design space, the workshop was divided into three sessions: encouraging participants to recall their start-up sequences which were discussed as a group; watching and discussing the contextual video; and working alone to document startup sequences on a personal timeline (Figure 6). Four people who took part in the workshop drove regularly and frequently used car-sharing services such as DriveNow or Zipcar. Both genders were represented and ages ranged from 24 to 40 years old.

For the Feeling in Control design space, the workshop collected detailed information about driver's perception of time and their emotional progression during long unfamiliar journeys divided into four sessions: storytelling a long journey and emotions during the journey; discussing driver's perception of time and space and 


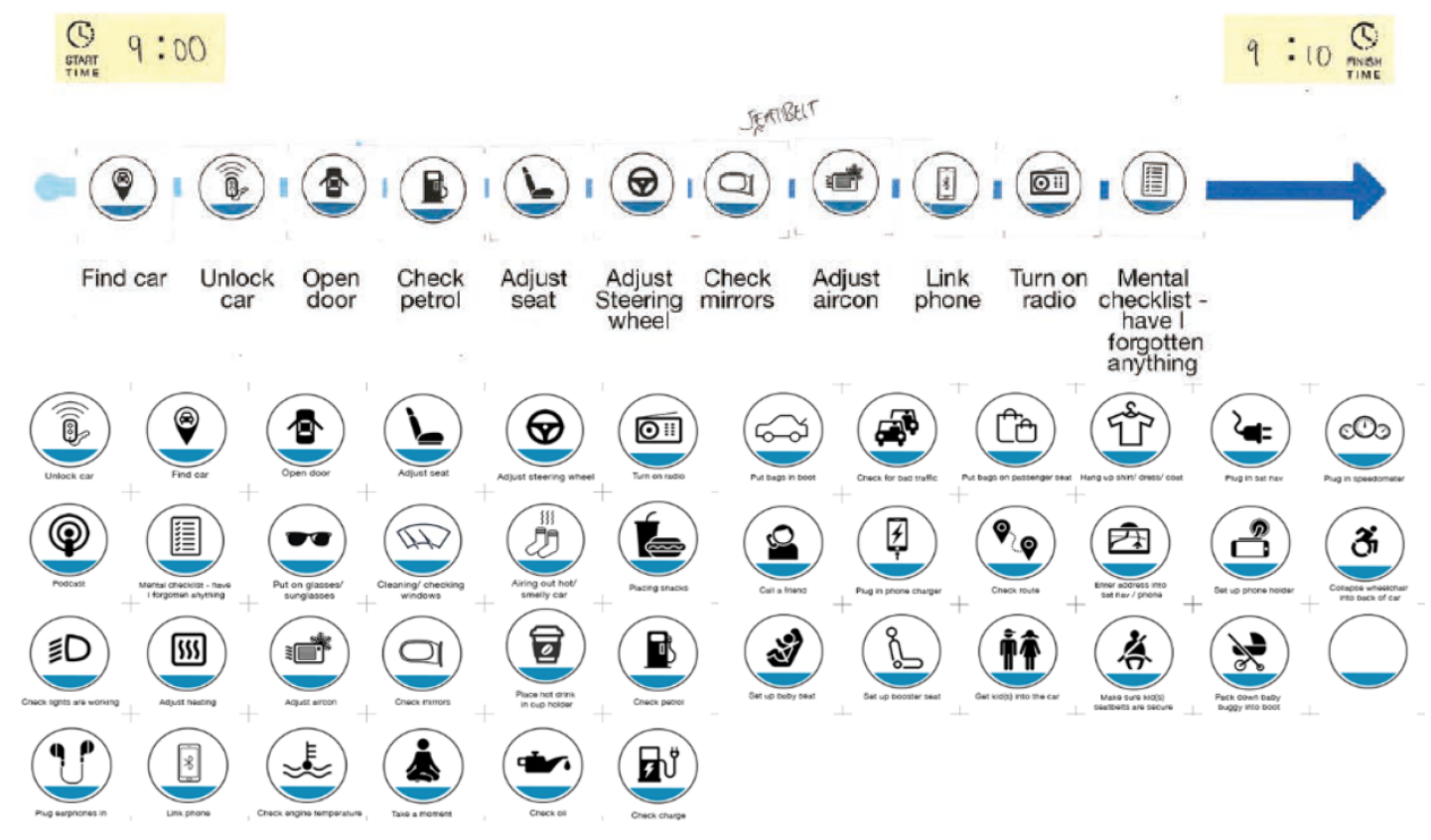

Figure 6: Top: Startup ritual timeline made by a workshop participant. Bottom: Icons used to illustrate start-up sequences.

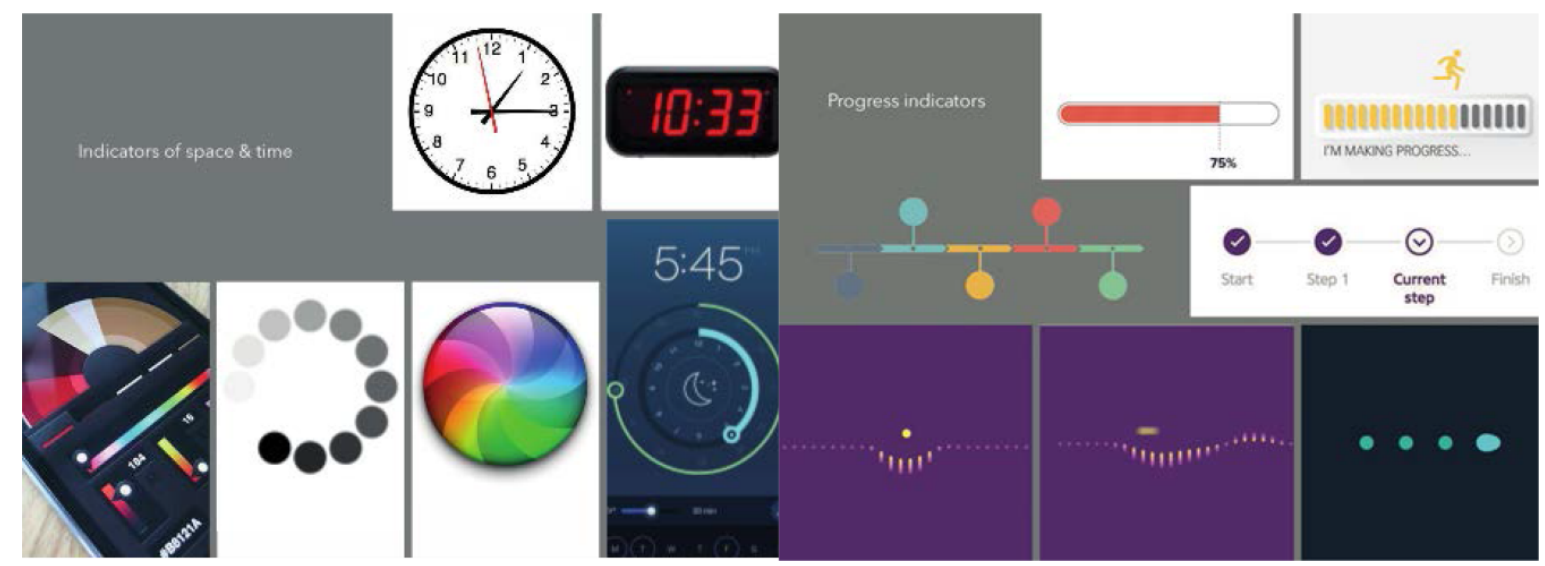

Figure 7: Selected images used to prompt participants to talk about and draw their own journey progress indicators

tools/agents to sense them (Figure 7); drawing preferred journey progress indication systems; watching contextual video for feedback. Five workshop participants (both genders, aged from twenties to sixties) all held a driving license and made long (more than two hours) unfamiliar car journeys outside cities where they live and work.

\section{DESIGN PROCESS}

\subsection{Creating design briefs and contextual videos}

'Good facts are only the starting point, good product design is actually built on the designers' interpretation of those facts' [12]. Having applied telephone interviews, enactment workshops and journey shadowing, we looked for design opportunities to enhance car users' experience by avoiding negative emotions or smoothing them away when they start to occur. Design briefs for the design spaces were drafted called 'Feeling ready' and 'Feeling in control'. We incorporated briefs detailing touch points users interacted with, interactive behaviours, environmental context and the implied emotions that the interactions support (Table 2). An ideation workshop immersed designers in the context of representative ritualistic emotional transition scenarios and created vehicle designs to address the design briefs 'emotional support' needs. Two design concepts were chosen and contextual videos generated to show users' situations, amplifying key interactions to improve and suggesting outlines of needs to be provided, but leaving specific improvements implicitly for later development. 
Table 2: Selected design briefs

\begin{tabular}{|c|c|c|}
\hline Design space & Emotional transition scenario example & Emotional support \\
\hline $\begin{array}{l}\text { Feeling } \\
\text { ready }\end{array}$ & $\begin{array}{l}\text { Every morning before taking a } 40 \text {-minute drive to work, M prepares his car. He } \\
\text { uses a range of gadgets and this habit gives him a sense of protection and control. } \\
\text { He attaches his dashcam to the windscreen, places his satellite navigation device } \\
\text { on the fascia, and cleans the windscreen and the vehicle's side mirrors to ensure } \\
\text { clarity of vision. }\end{array}$ & $\begin{array}{l}\text { These checks and the order they } \\
\text { are performed are important and } \\
\text { help him organise his space before } \\
\text { setting off, giving him peace of } \\
\text { mind while driving. }\end{array}$ \\
\hline $\begin{array}{l}\text { Feeling in } \\
\text { control }\end{array}$ & $\begin{array}{l}\text { S lives in the city centre and is driving to the countryside to meet a friend for } \\
\text { lunch on Sunday. She is taking a route that she loves to drive, and she knows the } \\
\text { road very well and is happy to make scenic detours if possible. As she leaves the } \\
\text { city her car responds to the changing environment by adjusting the interior space } \\
\text { physically and digitally based on the surroundings. Throttle response, seating, } \\
\text { lighting, steering weight, sounds, displays, suspension all adjust accordingly. } \\
\text { These changes happen gradually (not overpowering or distracting) to help her } \\
\text { feel more connected to both the car and the surrounding environment. }\end{array}$ & $\begin{array}{l}\text { The vehicle will be able to tailor } \\
\text { and adapt the driving experience to } \\
\text { maximise the feelings and emotions } \\
\text { of the individual's driving. }\end{array}$ \\
\hline
\end{tabular}
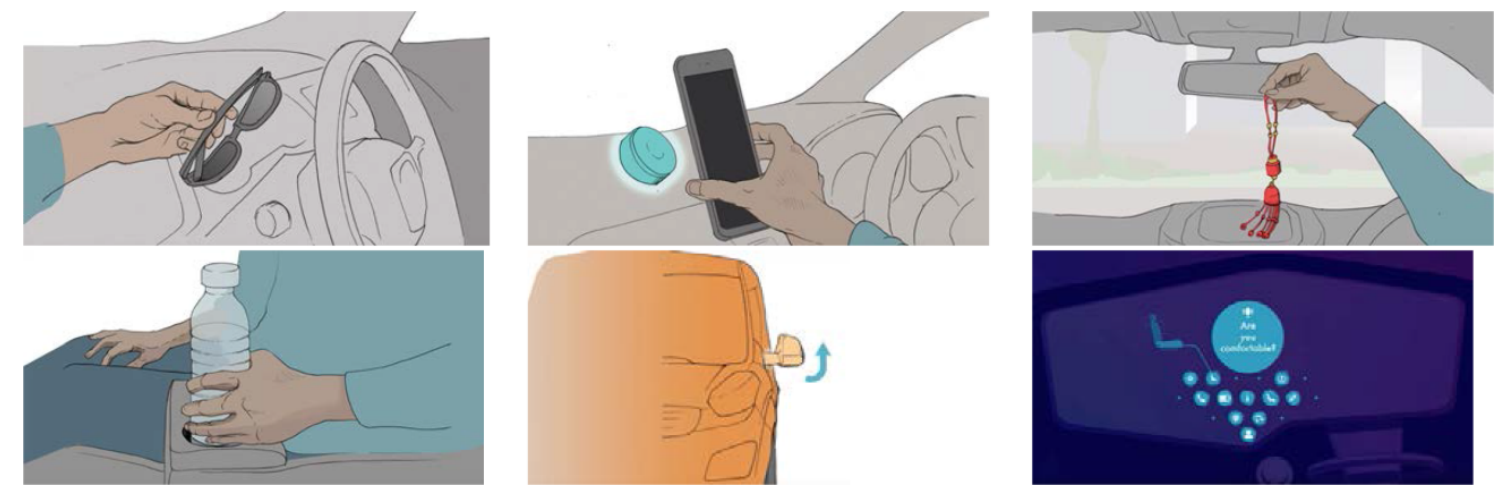

Figure 8: Contextual video Ready. . .Steady. . .Relax. A driver arranges their belongings around them supported by the vehicle (panels 1-4). The vehicle supports the adjustment of its mirrors and its dashboard interface (5 and 6).

The video 'Ready. . .Steady. . .Relax' (see Figure 8 and appendix) was created for the Feeling Ready design space. It is based on the research finding that many drivers describe the moment they get into a car, settle in and start driving as important/ritualistic emotional events that often extend to the rest of the day. Most people have a sequence to get a vehicle ready to drive, addressing comfort, safety, route planning and mental checklists. These can be a chore and take away from the joy of driving, however, if using an unfamiliar car it appears to be inevitable they perform much or all of their usual sequence as part of settling into an unfamiliar environment. These actions are hugely helpful when setting a driver's emotional state for an upcoming journey.

'Driving Whisper' (Figure 9 and appendix) for Feeling in Control reflects driving to an unfamiliar destination, the car adjusting its driving mode (for example, engaging autopilot) and other in-vehicle elements to relieve anxiety. It focusses on dashboard design for vehicle-user communication to relieve stress and make long-distance journeys more pleasant, particularly elapsed journey time, which we found affects moods and emotions, especially when driving to a new destination. Worry about lateness, tiredness, and stress related to the unknown length of the journey, all affect mood. Clocks, familiar landmarks and navigation tools can help calculate how much longer the journey will last but take attention away from the road. We identified strategies people use to help perceive how far through a journey they are, for example, checking if half way, estimating if it is ten minutes before their planned arrival time, continuously calculating the percentage of the time to complete the journey that has passed, with some people checking their overall progress every three to ten minutes.

\subsection{Developing in-vehicle interaction concepts}

The workshops collected detailed feedback about vehicle-user interactions with the aim of creating novel designs for in-car interfaces and displays and extended connected device functionality. Two video demos were created to communicate the interaction details between the vehicle objects/extended functions and the user.

4.2.1 Ready...Steady...Relax. We found when people talk about starting a car and ritualistic actions to release anxiety, frustrations around new cars are frequently addressed: 'changing car every time stressed me out. From the moment I get in I would just panic. I used to wait for the model I wanted.' One interviewee mentioned frustration with always having to move the driver's seat. Settling into an unfamiliar car is perfect for investigating the start-up process 

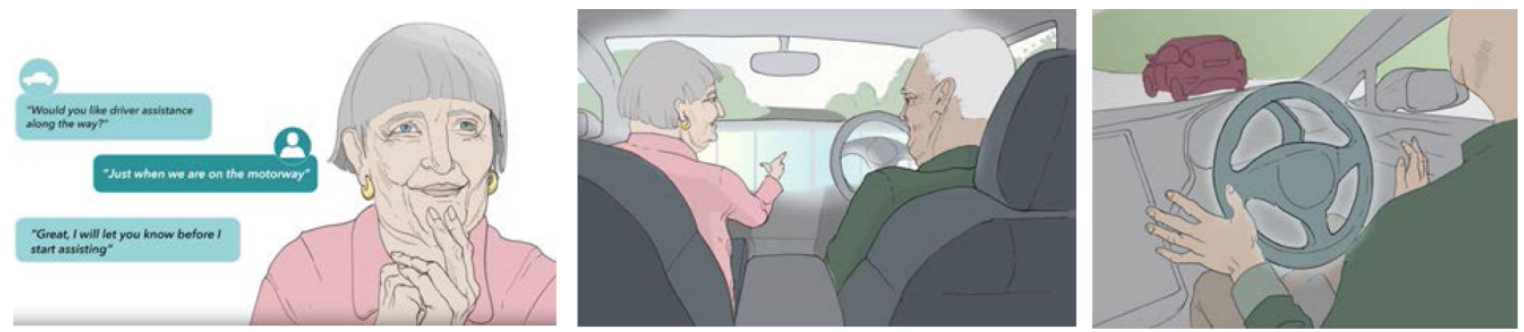

Figure 9: Driving Whisper contextual video. Left to right: communications between driver/passenger and the car about the level of driving assistance desired; dashboard lighting indicating assistance level; switching from driver mode to self-driving.

and related emotional transitions as it is relatively easy for drivers to identify difficulties that emotionally affect them.

We examined start-up sequences for drivers using a shared vehicle service or a new car. In terms of sequence, all four participants said placing their belongings, such as small bags, on the back/passenger seat or footwell was one of their first actions, followed by adjusting their seat and mirrors. Mid routine, people dealt with safety such as seatbelts and checking fuel/charge level. Everyone connected their smartphone, two participants as soon as they entered the car, one after arranging belongings. One made a point of always bringing a cable with him. Switching on satnavs and music/podcasts were final actions before setting off. Participants pointed out that their start-up process varied according to length of journey and whether it was a familiar or unfamiliar drive. For a long familiar drive people would spend time checking the car as well as making sure that they had some form of map and a phone charger. When asked how people would like the car to communicate with them, everyone preferred information to be delivered in a non-intrusive way.

We identified three features that could assist driver's emotional transitions before driving. First, when users order new or shared cars, their settings are automatically sent to the car. Next, when users sit in the car, safety related checks and automatic adjustment of seats, mirrors and wheel are made saving time and effort. Finally, leaving the choice of media playlist to the user instead of trying to guess and play would be beneficial as we found people wanted to make their own decisions to help ensure that they are in control. Customisation needs to be configured according to user's needs rather than being applied universally.

4.2.2 Driving Whisper. For checking journey time and progress, participants said they indicators such as natural light, route information on apps/maps, signposts and signs of their own physical or mental tiredness. Older participants tended not to use maps as they have "fairly good knowledge of where everything is", many mentioning signposts and landmarks as sufficient. Time perception is dramatically influenced by the sense of moving: if stuck in traffic time feels as if it moves more slowly than taking a longer route. When discussing potential progress indication systems, participants were asked to choose pre-made progress indicators and modify or draw their own. Designs preferred by most were progress bars indicating start to finish left to right, and maps indicating the car's position relative to key landmarks (Figure $10 \mathrm{a}, \mathrm{c}$ ). Indicating stops as a percentage of the journey or notifying the driver of potential places for breaks were very common in participants' drawings (Figure $10 \mathrm{~d}, \mathrm{e})$. Suggested progress indicator content varied depending on journey length, more detail requested for long journeys, less for shorter distances (Figure $10 \mathrm{~b}$ ). People differed in preference about colour choice for lights, some mentioned too many colours confuse, others suggested colours should be used to indicate different stages of a journey.

We identified a design space concentrating on displaying journey progress, an opportunity to design a timeline indicator displayed above the dashboard which does not distract a driver's attention from the road while noting major challenges during the drive and estimating journey time left. Our proposed display design is a threadlike timeline displayed as close to the eyeline as practical with a moving dot indicating whereabouts in the overall journey. To remove challenges that might cause driver stress we designed the indicator to announce upcoming traffic issues and nearby landmarks to help guide the driver's manoeuvres.

\section{FINDINGS}

During the process of exploring typical ritualistic actions that help avoid negative emotions to be built up or smooth out negative emotions, two common emotional transition scenarios emerged which represent neglected research areas: getting ready before a journey and feeling in control by monitoring journey progress. In this section, key findings and future design suggestions are summarised around these two areas.

\subsection{Preparations before a journey and design suggestions}

Before travelling people prepare, they organise their belongings as well as themselves and others. The emotions many described were feelings of anxiety, apprehension and stress. One mother said she feels anxious and distracted before a long journey with her partner and children. She is concerned that she will forget something. She organises food, clothes, toys and books to entertain the children as well as ensuring that she has keys, her mobile phone and charger with her in the vehicle. Others felt the opposite, such as feeling happy, excited and full of anticipation as they prepared for their journeys. One driver explained his pre-driving ritual centred around his car as he cleaned the windscreen and windows, switched on the satellite navigation, dashboard camera, heads-up-display and radio. When asked how significant their travel rituals were to 

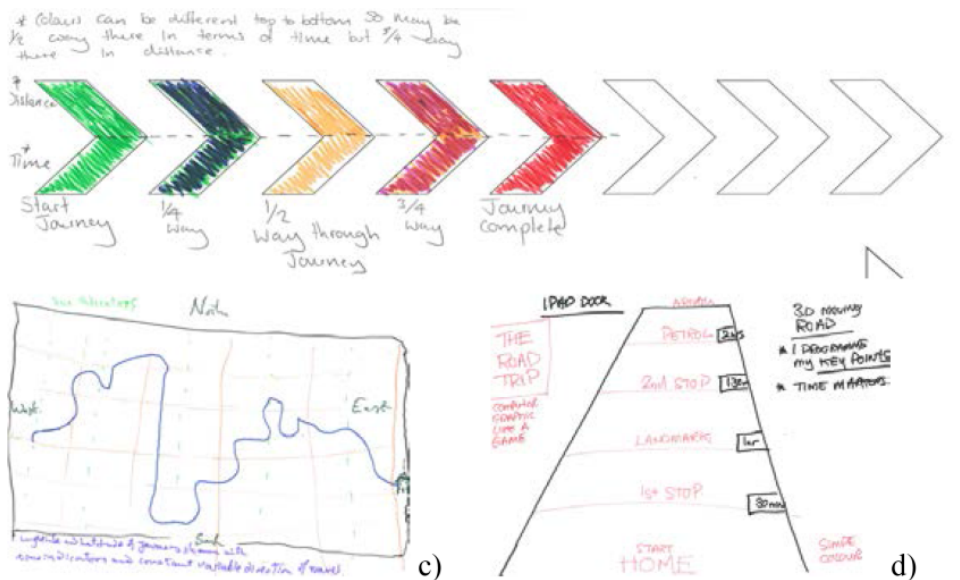

c)
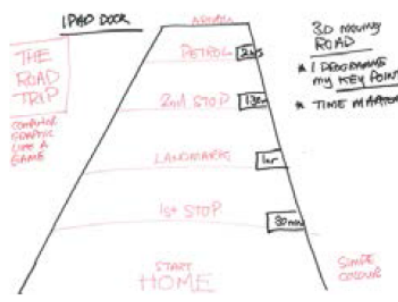

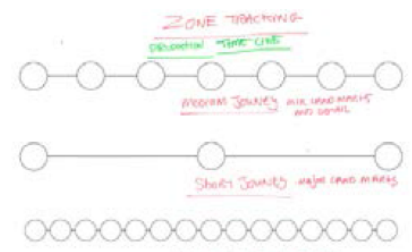

a)

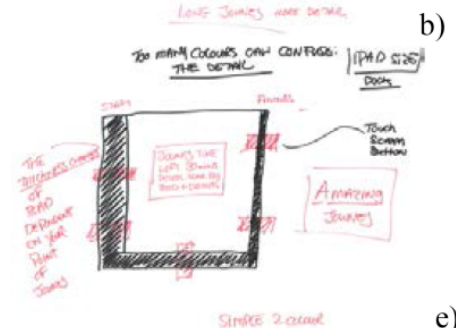

Figure 10: Preferred journey progress indication systems drawn by participants

Table 3: Pre-journey preparation sequence indicating vehicle object/area and user action(s)

\begin{tabular}{ll}
\hline Vehicle object/area & Action(s) \\
\hline 1. Boot & Placing larger luggage, gear, buggies in the boot \\
2. Driver and passenger area & Placing smaller items (backpacks, sunglasses, drinks/snacks) on seat, cup-holders or dash \\
3. Media & Turning on radio/CD player or podcast \\
4. Driver position adjustment & Adjusting seat, steering wheel and mirrors \\
5. Navigation & Setting up navigation and other gadgets or devices \\
6. Setting off & Start the car \\
\hline
\end{tabular}

Table 4: Journey progress display and design suggestions

\begin{tabular}{ll}
\hline $\begin{array}{l}\text { Design Elements for display/indication } \\
\text { Shape and movement of } \\
\text { progression indicator }\end{array}$ & $\begin{array}{l}\text { Design suggestions } \\
\text { Long horizontal display with left to right movement (suitable for left-to-right script locales); } \\
\text { Lighting colours }\end{array}$ \\
& $\begin{array}{l}\text { Map-like interface indicating the car and the destination with suggested key breakpoints } \\
\text { Everyone has different perception of colours and prefer some level of choice; Simple dim } \\
\text { lighting on the display is preferred }\end{array}$ \\
Information detail & $\begin{array}{l}\text { More details for long journeys and less for short ones; sometimes people do not want any } \\
\text { information when they are confident about a journey }\end{array}$ \\
Allow checking of entire route before leaving; show more detailed/frequent updates of route \\
Route display/confirmation
\end{tabular}

them and whether they are meaningful beyond being merely functional, answers included that the actions help to build confidence and mental preparation, make them feel relieved and in control, help travellers to be organised and look forward to the upcoming journey, and to switch off from their surroundings. In summary, people consider pre-journey preparations as a key ritualistic action providing a sense of order, familiarity and control.

5.1.1 Pre-journey preparation sequence. By observing participants getting into the car and all the actions they carried out before setting off, we identified the common sequence shown in Table 3

5.1.2 In-car comfort and user-vehicle communication. For most entry level cars, drivers felt forced to accept a standard interior and adapt themselves to it but were generally satisfied as it had become a familiar space. One user mentioned she did not feel the car had a welcoming interior, it had "a messy personality", suggesting some users need more customised communication when they first interact with a vehicle so they feel it is their car and that its features were designed for them.

\subsection{Journey progress indication and design suggestions}

Our study showed that people would prefer some level of personalisation and choice in how a journey's progress is displayed, with a preference to have information located on the dashboard or steering wheel. We summarise how the findings might inform the design of better displays indicating journey progression in Table 4 


\section{CONCLUSION}

This work focused on defining driver's emotional transitions with potential to negatively affect driving performance. People's state of mind often changes momentarily and unconsciously. Identify typical emotional transition scenarios and the turning point of the transition is key to unlock novel design opportunities for vehicle-user communication. By applying a research through design approach - investing ritual concept in user studies, visualising inquiries to improve quality of discussion, synthesising user demands into storytelling, we focused on two areas - pre-journey preparation and journey progress checking. These two areas have been addressed the most during our user engagement process that both contain frequent emotional transitions and have been overlooked from the perspective of in-vehicle interaction design.

Exploring ritualistic driving related moments with car users allowed us to enter their mental space and review repeated actions that help them conquer emotional challenges and might 'demonstrate that his or her actions mean more than they seem' [17]. They often describe the ritualistic actions associated with 'clear mind', 'process', 'checking' and 'wake up' which are closely related to managing emotions. Incorporating rituals led us to investigate details of pre-journey preparation sequence and journey progress perception which provide a new territory for designing adaptive car features around natural driving actions.

This paper presents a qualitative research project that follows the design research process, emphasising collecting qualitative user experience and contextual data for novel in-vehicle interaction design. The numbers of subjects cannot compare to most quantitative vehicle related research, which typically involves hundreds of surveys or collecting data from thousands of drivers. However, the uniqueness of our research is that the qualitative data we collect by immersing ourselves in users' experience provide much more detailed information including step-by-step actions, environment around the actions, touchpoints that drivers interact with, emotions behind each action and drivers of emotions. Instead of providing highly summarised emotions and drivers such as accidents, traffic and driving quality [3], the design research process highlights details, for instance, adjusting mirrors and seats or keeping children engaged during a long journey. This provides a panoramic picture for vehicle developers and inspires them with subtle details of 'unconscious rituals' for envisioning future directions. The limitation is that concepts need more user evaluation to confirm that the identified areas are typical demands and the proposed concepts are valid for most drivers.

From the design research perspective, the most difficult challenge is how to define and collect examples of emotional transitions as emotions consist of fragmented information and analysing them is challenging. As design researchers, our emotional involvement in scenarios that we summarise from data is key to generating creativity from our own interpretation of such experiences. Future research on creating tools to help recognise, define and collect examples of emotions and transfer the knowledge into design opportunities would be useful.

\section{ACKNOWLEDGMENTS}

This research was sponsored by Hyundai-Kia. We would like to thank Hyundai Motor's German and Korean offices for their involvement in feedback and review during the research.

\section{REFERENCES}

[1] Barrett, L. F. (2017). How emotions are made: The secret life of the brain. Houghton Mifflin Harcourt.

[2] Bossard, James H.S. \& Boll, Eleanor S. (1949). Ritual in Family Living. American Sociological Review, Vol. 14(No. 4 (Aug., 1949)), 463-469.

[3] Braun, M., Pfleging, B., \& Alt, F. (2018). A Survey to Understand Emotional Situations on the Road and What They Mean for Affective Automotive UIs. Multimodal Technologies and Interaction, 2(4), 75. https://doi.org/10.3390/mti2040075

[4.] Braun, M., Schubert, J., Pfleging, B., \& Alt, F. (2019). Improving Driver Emotions with Affective Strategies. Multimodal Technologies and Interaction, 3(1), 21. https://doi.org/10.3390/mti3010021

[5] Dewey, J. (1934). Art as experience (Perigee trade pbk. ed). Perigee.

[6] Eyben, F., Wöllmer, M., Poitschke, T., Schuller, B., Blaschke, C., Färber, B., \& Nguyen-Thien, N. (2010). Emotion on the Road-Necessity, Acceptance, and Feasibility of Affective Computing in the Car. Advances in Human-Computer Interaction, 2010, 1-17. https://doi.org/10.1155/2010/263593

[7] Forlizzi, J., \& Battarbee, K. (2004). Understanding experience in interactive systems. Proceedings of the 2004 Conference on Designing Interactive Systems Processes, Practices, Methods, and Techniques - DIS '04, 261. https://doi.org/10. 1145/1013115.1013152

[8] Forlizzi, J., Disalvo, C., \& Hanington, B. (2003). On the Relationship between Emotion, Experience and the Design of New Products. The Design Journal, 6(2), 29-38. https://doi.org/10.2752/146069203789355507

[9] Forlizzi, J., \& Ford, S. (2000). The Building Blocks of Experience: An Early Framework for Interaction Designers. DIS '00: Proceedings of the 3rd conference on Designing interactive systems: processes, practices, methods, and techniques, 419-423. https://doi.org/10.1145/347642.347800

[10] ] Gaver, B., Dunne, T., \& Pacenti, E. (1999). Design: Cultural probes. Interactions, 6(1), 21-29. https://doi.org/10.1145/291224.291235

[11] Gordon-Lennox, J. (2016). Crafting Secular Ritual: A Practical Guide. Jessica Kingsley Publishers.

[12] Holtzblatt, K. (2016). Contextual design: Design for life (2nd edn). Elsevier.

[13] Jeon, M., \& Walker, B. N. (2011). What to detect?: Analyzing Factor Structures of Affect in Driving Contexts for an Emotion Detection and Regulation System. Proceedings of the Human Factors and Ergonomics Society Annual Meeting, 55(1), 1889-1893. https://doi.org/10.1177/1071181311551393

[14] Karapanos, E., Zimmerman, J., Forlizzi, J., \& Martens, J.-B. (2009). User experience over time: An initial framework. Proceedings of the 27th International Conference on Human Factors in Computing Systems - CHI 09, 729.

[15] Marshall, D. (2005). Food as ritual, routine or convention. Consumption Markets \& Culture, 8(1), 69-85.

[16] Nass, C., Jonsson, I.-M., Harris, H., Reaves, B., Endo, J., Brave, S., \& Takayama, L. (2005). Improving automotive safety by pairing driver emotion and car voice emotion. CHI '05 Extended Abstracts on Human Factors in Computing Systems CHI '05, 1973. https://doi.org/10.1145/1056808.1057070

[17] Ozenc, Kursat and Hagan, Margaret. 2014. Ritual Design Lab. Retrieved August 10, 2018 from https://www.ritualdesignlab.org/

[18] Plutchik, R. (2003). Emotions and life: Perspectives from psychology, biology, and evolution (1st ed). American Psychological Association.

[19] Roider, F., Rümelin, S., Pfleging, B., \& Gross, T. (2017). The Effects of Situational Demands on Gaze, Speech and Gesture Input in the Vehicle. Proceedings of the 9th International Conference on Automotive User Interfaces and Interactive Vehicular Applications, 94-102. https://doi.org/10.1145/3122986.3122999

[20] Terken, Z., Haex, R., Beursgens, L., Arslanova, E., Vrachni, M., Terken, J., \& Szostak, D. (2013). Unwinding after work: An in-car mood induction system for semi-autonomous driving. Proceedings of the 5th International Conference on Automotive User Interfaces and Interactive Vehicular Applications - AutomotiveUI '13, 246-249. https://doi.org/10.1145/2516540.2516571

[21] Van der Zwaag, M. D., Janssen, J.H., Nass, C., Westerink, J.H.D.M., Chowdhury, S., de Waard, D. (2013). Using Music to Change Mood While Driving. Ergonomics, 2013, Vol. 56, No. 10, 1504 - 1514. http://dx.doi.org/10.1080/00140139.2013.825013

[22] Wilson, A., \& Tewdwr-Jones, M. (2019). Let's draw and talk about urban change: Deploying digital technology to encourage citizen participation in urban planning. Environment and Planning B: Urban Analytics and City Science. https://doi.org/ $10.1177 / 2399808319831290$

[23] Wu, J., Johnson, S., Hesseldahl, K., Quinlan, D., Zileli, S., Harrow, D. (2018). Defining Ritualistic Driver and Passenger Behaviour to Inform In-Vehicle Experiences. AutomotiveUI'18 Adjunct, September 23-25, 2018, Toronto, ON, Canada. https://doi.org/10.1145/3239092.3265944 


\section{A CONTEXTUAL AND DEMO VIDEOS}

\begin{tabular}{lll}
\hline Video screenshot & Title & Supplementary file link \\
& Ready. . .Steady. . Relax contextual video & Video 1 \\
& Driving Whisper contextual video & Video 2 \\
& Ready. . .Steady. . Relax video demo & Video 3 \\
& Driving Whisper video demo & Video 4 \\
\hline
\end{tabular}

